\title{
Primary gastric lymphoma in clinical practice 1973-1992
}

\author{
A F Muller, A Maloney, D Jenkins, F Dowling, P Smith, E M Bessell, P J Toghill
}

\begin{abstract}
This study assessed the presentation, treatment, and prognosis of primary gastric lymphoma in general hospital practice and its relation to infection with Helicobacter pylori. The number of patients that would on the current recommendations have been suitable for $H$ pylori eradication therapy was also examined. All lymphomas were graded according to a standard classification of gut lymphoma into high and low grade disease. Forty five patients (mean age 65 years) were identified. The overall five year survival was $40 \%$ with a trend in favour of an improved prognosis for low grade and stage I disease. $H$ pylori was present in $80 \%$. Only one of 18 patients with a low grade mucosa associated lymphoid tissue tumour had mucosal disease alone, which responded to omeprazole and amoxycillin. All other patients had bulk disease. These patients were treated by surgery, chemotherapy or radiotherapy or a combination of these treatments. In district hospital practice, most cases of primary gastric lymphoma have bulk disease at presentation. Even in patients with low grade gastric lymphoma on histological examination, many on the current evidence would not be suitable for anti-H pylori therapy alone.
\end{abstract}

(Gut 1995; 36: 679-683)

Keywords: Helicobacter pylori, primary gastric lymphoma.

University and City

Hospitals,

Nottingham

Departments of

Medicine

A F Muller

P J Toghill

Clinical Oncology

A Maloney

E M Bessell

and Histopathology

D Jenkins

P Smith

Department of

Pathology, King's Mill

Hospital, Sutton in

Ashfield

F Dowling

Correspondence to: Dr A F Muller,

The Kent and Canterbury

Hospital, Ethelbert Road,

Canterbury, Kent

CT1 3NG.

Accepted for publication

9 September 1994 Primary gastric lymphoma accounts for between $1-5 \%$ of all gastric malignancies. ${ }^{1}$ Even when confounding factors such as the decreased incidence of gastric carcinoma are taken into account the incidence of primary gastric lymphoma seems to be increasing. ${ }^{2-4}$ Survival has been shown to depend on the histological grade at presentation. ${ }^{5}$ Patients with low grade disease with low depth of infiltration and radical resectability of the gastric lymphoma have been shown to have the best prognosis. ${ }^{7} 8$ In a prospective study RuskonéFoumestraux et al ${ }^{9}$ showed that the combination of surgery and chemotherapy in patients with high grade disease was associated with an improved survival compared with patients treated with chemotherapy alone.

Recent interest in the relation between Helicobacter pylori and gastric carcinoma ${ }^{10}$ has prompted an analysis of the presence of this organism in patients with gastric lymphoma. Wotherspoon et al ${ }^{11}$ found a $92 \%$ incidence of
$H$ pylori in 110 patients with gastric lymphoma, an order similar to that found in patients with gastric carcinoma but much higher than in the general population. Many primary gastric lymphomas are now recognised to be $B$ cell lymphomas of mucosa associated lymphoid tissue (MALT). While MALT is not normally found in the gastric mucosa, it may develop after chronic inflammation such as is seen with $H$ pylori infection. It has been proposed that MALT, acquired in response to infection provides a background for the development of both gastric carcinoma and lymphoma. ${ }^{11-15}$ In five of six patients with low grade primary gastric lymphoma, $H$ pylori eradication therapy has been shown to lead to a regression of the lymphoma. ${ }^{13}$

Clinical experience in routine general hospital practice suggests that very few cases of primary gastric lymphoma, even in patients with low grade disease, present at such an early stage as those seen in a tertiary referral centre. ${ }^{13}$ This study aimed to assess whether there were two patterns of presentation for primary gastric lymphoma, the 'gastritis' type described by Wotherspoon et al ${ }^{13}$ and the 'tumour' type. We also assessed the presentation and importance of the stage and grade of these tumours at diagnosis, the bulk of the lesions, the prognosis, how the patients were treated (by radiotherapy or chemotherapy with or without surgery), and the proportion in which $H$ pylori was seen.

\section{Methods}

For the period 1973-1992 all cases of primary gastric lymphoma were identified from the matched with the histopathology records for all patients in Nottinghamshire (University, General, and City Hospitals in Nottingham and King's Mill Hospital, Sutton in Ashfield). All case notes were retrieved and details recorded of patient age, sex, presenting symptoms, date of diagnosis, size and type of tumour, treatment, and where relevant date of death. Results of computed tomography, bone marrow, and immunoglobulin results were also recorded. All histology specimens, either from endoscopic biopsies or surgically resected specimens were reviewed by two histopathologists (D J and F D) who were unaware of the original diagnoses.

\section{Diagnosis of primary gastric lymphoma}

The diagnosis of primary gastric lymphoma was based on the criteria described by Isaacson et al. ${ }^{16-18}$ In all patients the disease was predominantly localised to the stomach with 
Presenting symptoms of primary gastric lymphoma $(n=45)$. Most patients had epigastric pain

\begin{tabular}{lc}
\hline Symptom & $\%$ \\
\hline Epigastric pain & 93 \\
Weight loss & 56 \\
Anorexia & 31 \\
Vomiting & 27 \\
Melaena & 20 \\
Haematemesis & 16 \\
Anaemia (tiredness, breathlessness) & 13 \\
Backache & 9 \\
Nausea & 7 \\
\hline
\end{tabular}

involvement of draining gastric lymph nodes in some cases, thus also fitting the criteria of Dawson et al. ${ }^{19}$ Tumours were classified as being of MALT origin only when the characteristic lymphoepithelial changes, polymorphic cellular content, 'centrocyte like cells', and reactive germinal centres were seen in addition to the presence of B cell morphology and B cell markers on immunocytochemistry. MALT tumours were classified into low and high grade disease depending on the proportion of large, blast type cells present (high grade $>20 \%) .{ }^{20}$ When the characteristic features of MALT tumours were absent, samples were labelled as being $B$ cell lymphomas when $B$ cell morphology and markers were present.

Primary gastric lymphoma was staged according to the Ann Arbor classification (stage $\mathrm{I}_{\mathrm{E}}$, confined to the stomach; stage $\mathrm{II}_{\mathrm{E}}$ with local lymph node spread). The presence or absence of ' $B$ ' symptoms (which includes weight loss), was also recorded. Patients with secondary involvement of the stomach by either Hodgkin's disease or non-Hodgkin's lymphoma were excluded.

\section{Immunocytochemistry}

The tumours were classified as being of either $\mathrm{B}$ or $\mathrm{T}$ cell origin using the following immunocytochemical stains:

Pan-leucocyte common antigen (Dako LCA, 2B11, PD7, an antigen common to leucocytes).

$B$ cell markers: CD20 (Dako L26) and CD45R.

$T$ cell markers: CD45RO (UCHL 1), CD43 (Dako CD43) and CD3 (Dako polyclonal).

\section{Helicobacter pylori}

Histological material was examined from each patient for the presence or absence of $H$ pylori by $\mathrm{P} \mathrm{S}$ and $\mathrm{D} \mathrm{J}$. When $H$ pylori was not readily identified, further preparations using a Giemsa stain were performed. ${ }^{21-22}$

Life table analyses for overall and cause specific survival were performed for each disease grade using Kaplan-Meier survival curves.

\section{Results}

Fifty one patients were identified from the lymphoma registry and pathology records. Two patients were excluded from further analysis because of a revised diagnosis of carcinoma in one and disseminated non-Hodgkin's lymphoma with infiltration of stomach. Four other cases were excluded because no material was available for histopathological assessment in three and insufficient material to make a diagnosis in one leaving 45 patients for analysis. The mean (SD) age of the group was 65 (11) years and the range 25-84. The male: female ratio was 1:5:1.

\section{Presenting symptoms (Table)}

These were similar to gastric cancer. The predominant symptom was that of epigastric pain.

\section{Histopathology}

All of the tumours were of $B$ cell origin. Twenty five were stage $\mathrm{I}\left(\mathrm{I}_{\mathrm{EA}}: 12, \mathrm{I}_{\mathrm{EB}}: 13\right)$, and 20 were stage $\mathrm{II}\left(\mathrm{II}_{\mathrm{EA}}: 5, \mathrm{II}_{\mathrm{EB}} 15\right)$ disease. There were 16 low grade and 17 high grade confirmed B cell MALT lymphomas. Of the remaining 12,10 were of high grade $B$ cell origin and two were low grade $B$ cell tumours. Most of the B cell tumours (11 of 12) were ulcerated lesions with no epithelial or only very occasional epithelial glands, 'centrocyte like cells' or reactive germinal centres making it impossible to make an assessment of MALT status although many may have been MALT tumours. Because of the small numbers involved for tumour type, they have been combined for the analysis. Only one of 18 patients with low grade primary gastric lymphoma had mucosal disease alone. All except this patient had bulk disease with mainly exophytic and ulcerated gastric lesions with serosal spread most commonly in the gastric body and antrum.

\section{Helicobacter pylori}

Ten of 45 patients were excluded from an assessment of $H$ pylori status because of ulcerated tumours with little or no mucosal tissue present in eight and two patients had been treated with a bismuth compound (which can suppress the growth of $\mathrm{H}_{\text {pylori }}{ }^{22}$ ) immediately before the diagnosis of primary gastric lymphoma was established. Of the remaining 35 patients, $H$ pylori was present in $28(80 \%)$.

\section{Treatment}

Four patients received no treatment; two died before surgical intervention and two elderly patients were considered too frail for therapy. The patient with mucosal disease was initially thought to have a $H$ pylori associated gastritis and was treated with anti- $H$ pylori eradication therapy consisting of omeprazole $40 \mathrm{mg}$ once daily for one month together with amoxycillin $500 \mathrm{mg}$ four times daily for two weeks. The diagnosis of low grade $B$ cell primary gastric lymphoma was confirmed by immunocytochemistry. Two follow up endoscopies with multiple gastric biopsies showed no evidence of primary gastric lymphoma and he has remained well for two years since the original diagnosis.

Nineteen patients had surgery, which in most was a partial gastrectomy. There were 


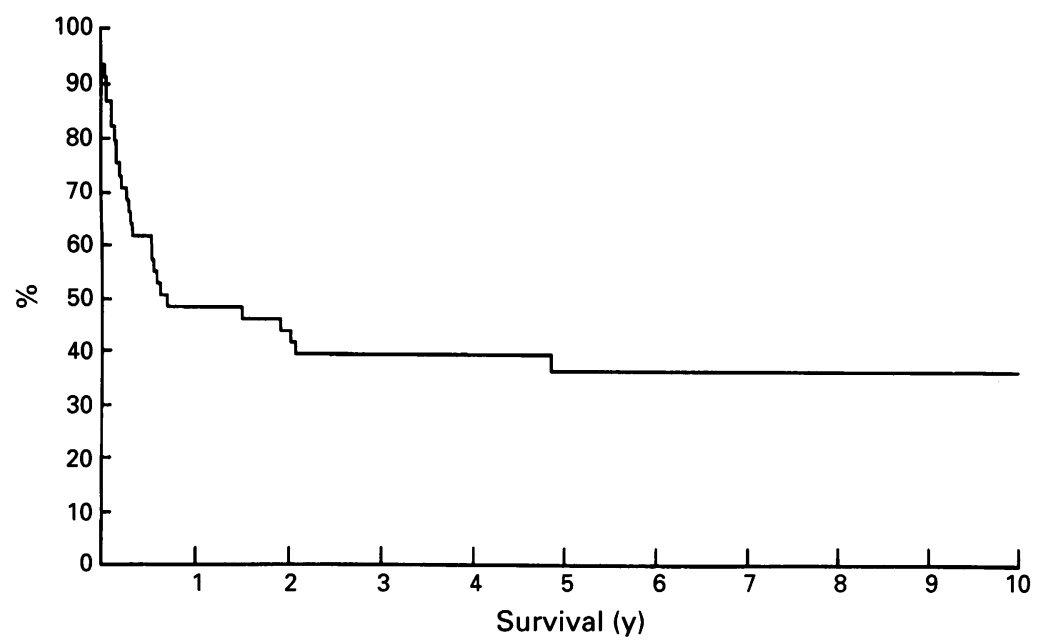

Figure 1: Overall survival in patients with primary gastric lymphoma irrespective of treatment given. The five year survival was $40 \%$. There were five deaths from other causes.

three postoperative deaths. Of the remaining 16 patients all except one were electively given postoperative chemotherapy $(n=10)$ or radiotherapy $(n=5)$.

Twenty one patients did not undergo surgery but were treated with either chemotherapy or radiotherapy (or a combination of the two). The chemotherapy treatment in these patients was tailored to the histological grade of the tumour and the age of the patient. Six patients with low grade disease were treated with chlorambucil alone. Patients in whom there was concern about the cardiotoxicity of adriamycin (typically the frail and the elderly) were treated with the MCOP regimen (mitozantrone, cyclophosphamide, vincristine, and prednisolone).$^{23}$ Thirteen patients were treated with CHOP (cyclophosphamide, adriamycin, vincristine, and prednisolone) or a CHOP variant. ${ }^{24}$ One patient was treated with a combination of ifosfamide and mitozantrone. ${ }^{25}$

Two patients died from second tumours (carcinomas) different from their original lymphoma.

The overall five year survival for the group irrespective of stage, grade of tumour or treatment was $40 \%$ (Fig 1). Figure 2 shows that there was no difference in cause specific survival between low and high grade lymphomas.

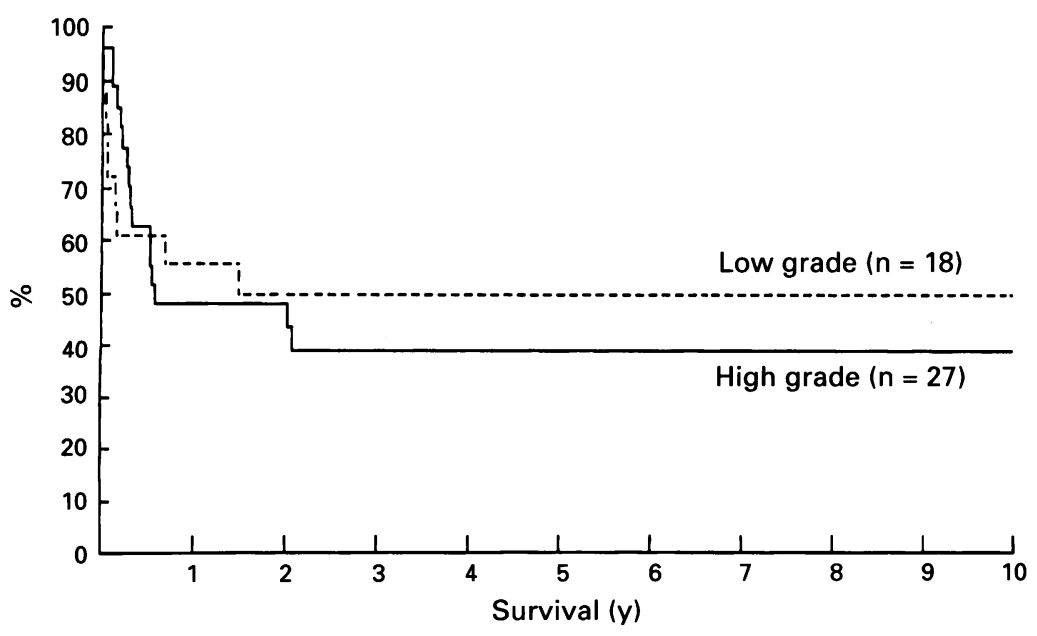

Figure 2: Cause specific survival in patients with primary gastric lymphoma according to grade of tumour. There was no difference between high and low grade disease.
There was a non-significant trend for improved survival in both patients with stage I disease $(\mathrm{p}<0 \cdot 1$, Fig 3$)$ and those who had received surgery as part of their treatment compared with those treated medically (Fig 4).

\section{Discussion}

This study examined the presentation of primary gastric lymphoma in district general hospital practice. It is probably representative of that seen by many gastroenterologists compared with that seen in specialist tertiary referral centres. At diagnosis, most cases had bulk disease with ulcerating tumours invading through the serosa. Only one patient with low grade primary gastric lymphoma had a 'gastritis' type histology. The infiltration of the stomach may have been greater than could be appreciated from the endoscopic biopsies and computed tomography, but endoscopic ultrasound, which may be of benefit in assessing depth of invasion, was not available.

It is possible that early MALT tumours are being missed because of their non-specific 'gastritis' type appearance at endoscopy. We believe, however, that it is unlikely that we have missed significant progressive disease as none of the patients had a previous histological diagnosis of 'gastritis'. None the less, for patients with unexplained symptoms in the presence of gastritis, biopsy specimens should be taken. We do not know if some patients presenting in the earlier part of this study, when immunocytochemistry was not available, may have been misclassified as carcinoma.

Hussell et al ${ }^{12}$ have shown that the proliferation of low grade B cell primary gastric lymphoma is dependent upon specific activation of $\mathrm{T}$ cells by $H$ pylori together with the release of cytokines that drive $B$ cell activation and proliferation. In five of six cases of low grade primary gastric lymphoma, Wotherspoon et al ${ }^{13}$ saw regression of the lymphoma after successful eradication of $H$ pylori. These findings prompted the recommendation that patients with low grade disease should receive $H$ pylori eradication therapy as a first line treatment with prolonged follow up rather than the conventional surgery, chemotherapy or radiotherapy. ${ }^{13} 14$

The patients included in the study by Wotherspoon et al ${ }^{13}$ probably represented very early disease, as the endoscopic appearances were those of 'gastritis' with biopsies showing lymphoepithelial destruction with the monoclonality of tumour cells confirmed by polymerase chain reaction. At present, no information is available as to whether it is only early MALT tumours that respond to $H$ pylori eradication therapy but in our series only one of 18 patients with low grade primary gastric lymphoma fitted that category. Our case of regression of lymphoma with omeprazole and amoxycillin agrees with the findings of Wotherspoon et al ${ }^{13}$ but it seems that patients only infrequently present with such disease. We do not know whether anti-H pylori therapy may result in tumour regression in patients with low grade bulk disease, but it is less likely 


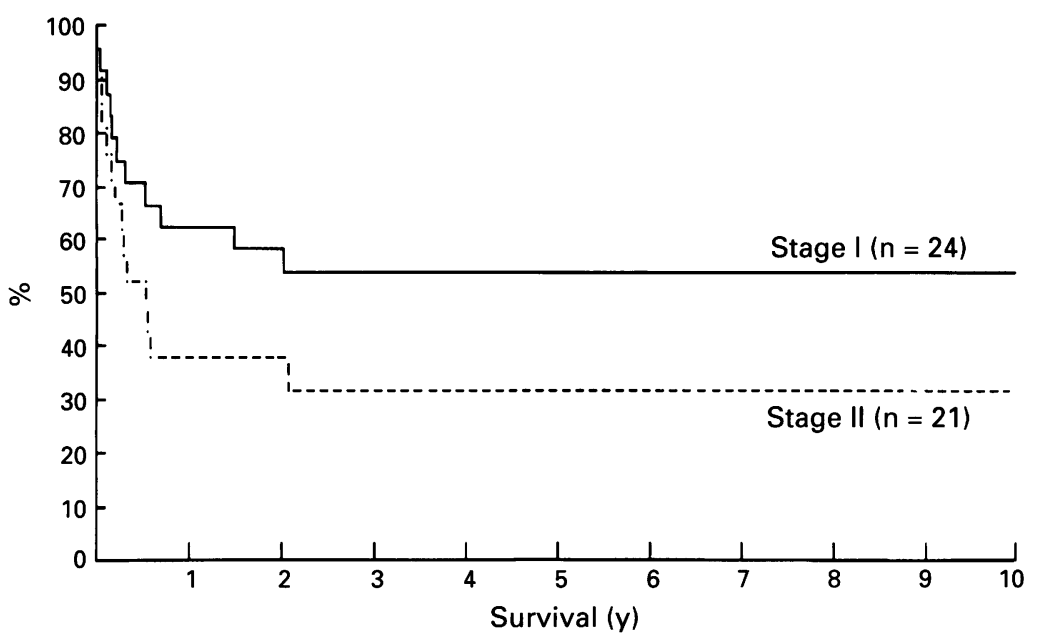

Figure 3 Cause specific survival in patients with primary gastric lymphoma according to stage of disease (NS). tolerated monochemotherapy with good outcome. In some cases, anti- $H$ pylori treatment may replace chemotherapy.

Chemotherapy or radiotherapy alone without surgery, or both, ${ }^{27-30}$ may improve the survival of patients with primary gastric lymphoma but patient numbers have been small. For those treated surgically, Radaszkiewicz et $a l^{8}$ showed that postoperative radiotherapy/or chemotherapy, or both, significantly improved survival although this was not confirmed by Cogliatti et $a l^{7}$ in a smaller group of patients. In patients with high grade lymphoma, Salles et $a l^{31}$ showed that surgical resection before the administration of chemotherapy did not influence response rate or survival. However, Ruskoné-Foumestraux et $a l^{9}$ in a study of 91 patients with gastrointestinal lymphoma, two thirds of which were primary gastric lymphomas, showed that the combination of radical surgery and those patients treated with chemotherapy alone.

The small numbers in each histological category in this study, prevent us from assessing the benefits of one treatment over another. The trend in favour of surgery probably reflects differences between the two groups of patients in age and disease stage but does agree with the results of Radaszkiewicz's and RuskonéFoumestraux's studies.

Some studies have suggested that patients with low grade disease have a better prognosis ${ }^{7}$ but in this series, cause specific survival (identifying patients dying from their disease rather than unrelated causes) was no different in high and low grade tumours. Although there was insufficient evidence histologically to confirm a MALT origin for 12 of our lymphoma cases, it is probable that many of these B cell tumours may have arisen from MALT and we therefore believe we are justified in combining the two groups for the analysis.

This retrospective series of patients with primary gastric lymphoma in Nottinghamshire over a 20 year period has shown that most cases presented with advanced ulcerating tumours with only one patient having a 'gastritis' type lesion. This pattern probably reflects district general hospital practice rather than that seen at tertiary centres. Our study has identified a need for further data on larger numbers of gastric lymphomas. The United Kingdom lymphoma group/British National Lymphoma Investigation are currently embarking on two studies that could achieve these objectives (Souhami and Leyland).

$H$ pylori is present in most primary gastric lymphomas and may be cofactor in the pathogenesis. Patients with low grade 'gastritis' type primary gastric lymphoma may be treated by $H$ pylori eradication therapy and regular follow up, a simple therapeutic strategy that has been shown to lead to tumour regression. Most patients on the evidence currently available could not be treated by this strategy alone and at present, should be treated using currently accepted protocols.

to benefit patients with high grade disease, chemotherapy was associated with a signifi-
where cell proliferation might be expected to cantly improved outcome in comparison with

to benefit patients with high grade disease, chemotherapy was associated with a signifi-
where cell proliferation might be expected to cantly improved outcome in comparison with

Figure 4: Survival in primary gastric lymphoma in patients treated with surgery (with or without additional chemotherapy or radiotherapy, or both) compared with those that received medical treatment alone. There were three postoperative deaths. The trend in favour of surgery probably represents selection bias and the patients were not well matched for age or stage of disease. continue ins. 
The authors acknowledge the help of Mrs J Thornley for retrieval of case notes and data and to the British National Lymphoma Investigation for their help with many of these cases at the time of presentation.

This work was presented in abstract form at the British Society of Gastroenterology Spring meeting at UMIST 1994 and at the American Gastroenterological Association Annual meeting in New Orleans, May 1994.

1 Loehr WS, Mujahed Z, Zahn FD, Gray GR, Thorbjarnarson B. Primary lymphoma of the gastrointestinal tract: a review of 100 cases. Ann Surg 1969 170: 232-8.

2 Sandler RS. Primary gastric lymphoma: a review. $A m \mathcal{F}$ Gastroenterol 1984; 79: 21-5.

3 Hayes J, Dunn E. Has the incidence of primary gastric lymphoma increased? Cancer 1989; 63: 2073-6.

4 Severson RK, Davis S. Increasing incidence of primary gastric lymphoma. Cancer 1990; 66: 1283-7.

5 Hockey MS, Powell J, Crocker J, Fielding JW. Primary gastric lymphoma. Br f Surg 1987; 74: 483-7.

6 Castrillo JM, Montalban C, Obeso G, Piris MA, Rivas MC Gastric B-cell mucosa associated lymphoid tissue lymphoma: a clinicopathological study in 56 patients. Gut 1992; 33: 1307-11

7 Cogliatti SB, Schmid U, Schumacher U, Eckert F, Hansmann M-L, Hedderich J, et al. Primary B-cell gastric lymphoma: a clinicopathological study of 145 patients. lymphoma: a clinicopathological study

8 Radaszkiewicz T, Dragnosics B, Bauer P. Gastro-intestinal malignant lymphomas of the mucosa-associated lymphoid
tissue: factors relevant to prognosis. Gastroenterology 1992; 102: $1628-38$.

9 Ruskoné-Foumestraux A, Aegerter P, Delmer A, Brousse N, Galian A, Rambaud J-C. Primary digestive tract lymphoma: a prospective multicentric study of 91 patients Gastroenterology 1993; 105: 1162-71.

10 Parsonnet J, Friedman GD, Vandersteen DP, Chang Y, Vogelman $\mathrm{JH}$, Orentreich $\mathrm{N}$, et al. Helicobacter pylori infection and the risk of gastric carcinoma. N Engl $\mathcal{F} M e d$ 1991; 325: 1127-31.

11 Wotherspoon AC, Ortiz-Hidalgo C, Falzon M, Isaacson PG. Helicobacter pylori-associated gastritis and primary PG. Helicobacter pylori-associated gastritis and prima

12 Hussell T, Isaacson PG, Crabtree JE, Spencer J. The response of cells from low-grade B-cell gaștric lymphomas of mucosa-associated lymphoid tissue to Helicobacter pylori. Lancet 1993; 342: 571-4.

13 Wotherspoon AC, Doglioni C, Diss TC, Pan L, Moschini $\mathrm{A}$, de Boni $\mathrm{M}$, et al. Regression of primary low-grade-Bcell gastric lymphoma of mucosa-associated lymphoid tissue type after eradication of Helicobacter pylori. Lancet 1993; 342: 575-7.

14 Stolte M, Eidt S. Healing gastric MALT lymphomas by eradicating $\mathrm{H}$ pylori. Lancet 1993; 342: 568.

15 Isaacson PG. Gastric lymphoma and Helicobacter pylori. $N$ Engl f Med 1994; 330: 1310-1.

16 Isaacson PG, Wright DH. Extranodal lymphoma. In:
Anthony P, Macsween RNM, eds. Recent advances in histopathology. London: Churchill-Livingstone, 1987: 159-84. 17 Isaacson PG, Spencer J, Finn T. Primary B-cell gastric lymphoma. Hum Pathol 1986; 17: 72-82.

18 Isaacson PG, Spencer J, Wright DH. Classifying primary gut lymphomas. Lancet 1988; ii 1148-9.

19 Dawson IMP, Cornes JS, Morson BC. Primary malignant lymphoid tumours of the intestinal tract. Br f Surg 1961; 49: 80-9.

20 Hall PA, Jass JR, Levison DA, Morson BC, Shepherd NA, Sobin LH, et al. Classification of primary gut lymphomas (letter). Lancet 1988; ii: 958.

21 Gray SF, Wyatt JI, Rathbone BJ. Simplified techniques for identifying campylobacter pyloridis. F Clin Pathol 1986; 39: $1279-80$.

22 Coghlan J, Hutchinson L, Gilligan D, Mckenna D, Keane C, Sweeney E, et al. Dosage of colloidal bismuth subcitrate in duodenal ulcer healing and clearance of citrate in duodenal ulcer healing and clearance of 49-54.

23 Bessell EM, Coutts A, Fletcher JF. Toghill PJ, Maloney AJ, Ellis IO, et al. Non-Hodgkins lymphoma in elderly patients: a phase II study of MCOP chemotherapy in patients aged 70 years and over with intermediate or high grade histology. Eur $\mathcal{F}$ Cancer 1994; 30A: 1337-41.

24 McKelvey EM, Gottlieb JA, Wilson HE, Haut A, Talley $\mathrm{RW}$, Stephens R, et al. Hydroxydaunomycin (Adriamycin) combination chemotherapy in malignant lymphoma. Cancer 1976; 38: 1484-93.

25 Dovey GJ, Child JA, Simmons AV, Barnard DL, Parapia L, Morgan $\mathrm{M}$, et al. Ifosfamide and mitozantrone (I-M) in relapsed and refractory high grade non-Hodgkin's lymrelapsed and refractory high grade non-Hodgkin's lymphoma 205 .

26 Parsonnet J, Hansen S, Rodriguez BS, Gelb AB, Warnke $\mathrm{RA}$, Jellum E, et al. Helicobacter pylori infection and gastric lymphoma. N Engl f Med 1994; 330: 1267-70.

27 Blazquez $M$, Haioun C, Chaumette M-T, Gaulard P, Reyes F, Soulé J-C, et al. Low grade B cell mucosa associated lymphoid tissue lymphoma of the stomach: clinical and endoscopic features, treatment and outcome. Gut 1992; 33: 1621-5.

28 Maor MH, Velasquez WS, Fuller LM, Silvermintz KB Stomach conservation in stages I E and II E gastric nonStomach conservation in stages I E and II E gastric no

29 Burgers JMV, Taal BG, van Heerde P, Somers R, den Hartog Jager FCA, Hart AAM, et al. Treatment results of primary stage I and II non Hodgkin's lymphoma of the stomach. Radiother Oncol 1988; 11: 319-26.

30 Swaroop VS, Mohandas KM, Swaroop D, Soman CS, Jagannath P, Desouza LJ. Treatment of primary gastric lymphoma. Gastroenterology 1993; 105: 645-6.

31 Salles G, Herbrecht R, Tilly H, Berger F, Brousse N, Gisselbrecht $\mathrm{C}$, et al. Aggressive primary gastrointestinal lymphomas: review of 91 patients treated with the LHN84 regimen. A study of the group d'etude des lymphomes aggressifs. Ann $\mathcal{F}$ Med 1991; 90: 77-84. 